\title{
Role of Bassoon and Piccolo in Assembly and Molecular Organization of the Active Zone
}

\author{
Eckart D. Gundelfinger ${ }^{1,2,3,4 *}$, Carsten Reissner ${ }^{5}$ and Craig C. Garner ${ }^{6,7 *}$ \\ ${ }^{1}$ Department Neurochemistry and Molecular Biology, Leibniz Institute for Neurobiology, Magdeburg, Germany, ${ }^{2}$ Center for \\ Behavioral Brain Sciences, Magdeburg, Germany, ${ }^{3}$ Medical Faculty, Otto von Guericke University, Magdeburg, Germany, \\ ${ }^{4}$ German Center for Neurodegenerative Diseases (DZNE) Site Magdeburg, Magdeburg, Germany, ${ }^{5}$ Institute of Anatomy and \\ Molecular Neurobiology, Westfälische Wilhelms University, Münster, Germany, ${ }^{6}$ German Center for Neurodegenerative \\ Diseases (DZNE) Site Berlin, Berlin, Germany, ${ }^{7}$ Charité Medical University, Berlin, Germany
}

Bassoon and Piccolo are two very large scaffolding proteins of the cytomatrix assembled at the active zone (CAZ) where neurotransmitter is released. They share regions of high sequence similarity distributed along their entire length and seem to share both overlapping and distinct functions in organizing the CAZ. Here, we survey our present knowledge on protein-protein interactions and recent progress in understanding of molecular functions of these two giant proteins. These include roles in the assembly of active zones (AZ), the localization of voltage-gated $\mathrm{Ca}^{2+}$ channels (VGCCs) in the vicinity of release sites, synaptic vesicle (SV) priming and in the case of Piccolo, a role in the dynamic assembly of the actin cytoskeleton. Piccolo and Bassoon are also important

OPEN ACCESS

Edited by:

Lucia Tabares,

University of Seville, Spain

Reviewed by:

Carlo Sala,

CNR Institute of Neuroscience, Italy Hiroshi Nishimune, University of Kansas Medical School, USA

*Correspondence: Eckart D. Gundelfinger gundelfi@lin-magdeburg.de; Craig C. Garner craig-curtis.garner@dzne.de

Received: 10 November 2015 Accepted: 14 December 2015 Published: 12 January 2016

Citation:

Gundelfinger $E D$, Reissner $C$ and Garner CC (2016) Role of Bassoon and Piccolo in Assembly and Molecular Organization of the Active Zone.

Front. Synaptic Neurosci. 7:19. doi: 10.3389/fnsyn.2015.00019 for the maintenance of presynaptic structure and function, as well as for the assembly of CAZ specializations such as synaptic ribbons. Recent findings suggest that they are also involved in the regulation activity-dependent communication between presynaptic boutons and the neuronal nucleus. Together these observations suggest that Bassoon and Piccolo use their modular structure to organize super-molecular complexes essential for various aspects of presynaptic function.

Keywords: Bassoon, Piccolo, Aczonin, cytomatrix at the active zone, neurotransmitter release, synapto-nuclear signaling, actin dynamics, synaptic vesicle

\section{INTRODUCTION}

Synapses are sophisticated cellular devices designed for the efficient and rapid communication between neurons via the regulated release of neurotransmitter substances from presynaptic boutons and their detection by postsynaptic receptor systems. The release of neurotransmitters is mediated by the recruitment and fusion of synaptic vesicles (SVs) at specialized regions of the presynaptic plasma membrane called active zones (AZ). The molecular and ultra-structural characterization of these release sites revealed that they are composed of a dense cytomatrix assembled at the AZ (CAZ). This matrix is organized by a small number of multi-domain proteins, including Munc13s, Rab3-interacting molecules (RIMs), RIM-binding proteins (RBPs), Liprins- $\alpha$, ELKS2/CAST as well as the two large scaffolding proteins Bassoon and Piccolo (aka Aczonin; Figure 1) (Garner et al., 2000; Schoch and Gundelfinger, 2006; Gundelfinger and Fejtova, 2012; Südhof, 2012; Ackermann et al., 2015). This review will focus on the contributions of Bassoon and Piccolo to the molecular and functional organization of the CAZ. 
Bassoon and Piccolo were originally discovered in a screen designed to identify structural components of rat brain synaptic junctions (Cases-Langhoff et al., 1996; Langnaese et al., 1996). Their molecular characterization revealed that they are structurally related multi-domain proteins including ten highly conserved regions, Piccolo-Bassoon homology domains (tom Dieck et al., 1998; Wang et al., 1999; Fenster et al., 2000). Initially these molecules were thought to be vertebrate specific, however,

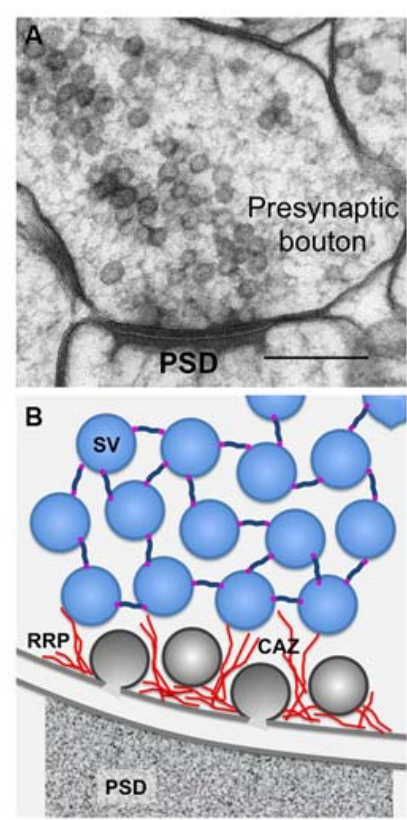

Bassoon
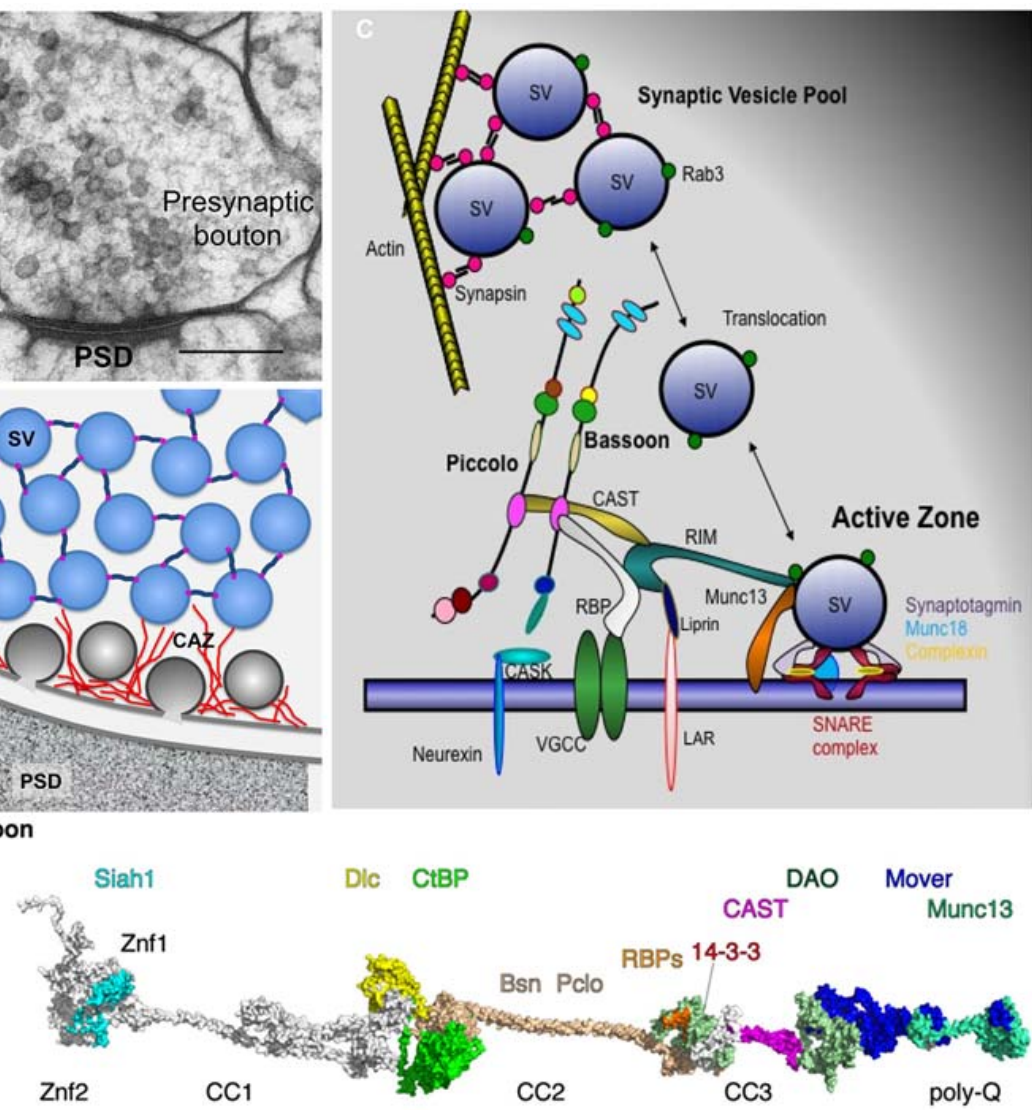

D

Piccolo

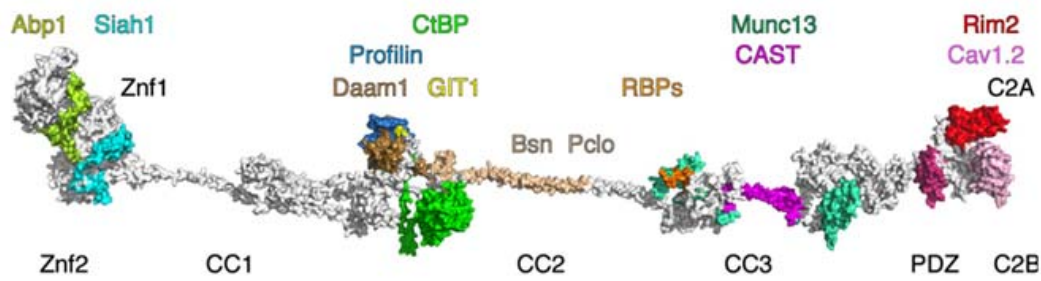

$80 \mathrm{~nm}$

FIGURE 1 | Piccolo and Bassoon at presynaptic active zones (AZ). (A) Cryo-electron micrograph of an excitatory synapse from rat brain (originally published in Rostaing et al., 2006; size bar, 200 nm). (B) Schematic organization of SVs within presynaptic boutons with SVs in the reserve pool tethered together via synapsin and those in the docked pool embedded in the CAZ (red filaments). (C) Schematic of CAZ molecules directing the clustering, translocation, docking, positional and molecular priming and fusion of SVs. (D) In-silico modeling of Bassoon and Piccolo structures with docking sites for binding partners color coded. The structures include X-ray and NMR data for Znf [protein data bank (Berman et al., 2000), PDB entry: 1ZBD], PDZ (1UJD), coiled-coil (3QH9 and Gruber and Lupas, 2003) and C2 (1RH8, 5CCG) domains. Piccolo C-terminus has been arranged similar to synaptotagmin (Zhou et al., 2015). Most of the remaining parts contain proline and glycine residues that prevent persistent folding but build compact distorted domains (Quiroz and Chilkoti, 2015), while the homologs coiled-coil helices elongate both proteins to about $80 \mathrm{~nm}$. These domains were modeled ab initio using threading (Kelley and Sternberg, 2009) and BLAST routines (Sauder and Dunbrack, 2000) and visualized using PyMOL (https://www.pymol.org). For further details compare Table 1. Abbreviations: PSD, postsynaptic density; SV, synaptic vesicle; RRP, releaseready SV pool; CAZ, cytomatrix assembled at the active zone. 
structurally more distantly related versions are also found in invertebrates, i.e., Fife and Bruchpilot (Wagh et al., 2006; Sigrist and Schmitz, 2011; Bruckner et al., 2012; Ackermann et al., 2015) that may serve similar functions in the CAZ. In vertebrates, Piccolo and Bassoon are selectively localized to the AZs of central and peripheral synapses as well as peptide/proteinsecreting cells of the endocrine system (Cases-Langhoff et al., 1996; tom Dieck et al., 1998, 2005; Brandstatter et al., 1999; Richter et al., 1999; Dick et al., 2001, 2003; Fujimoto et al., 2002; Haeberle et al., 2004; Nishimune et al., 2004; Shibasaki et al., 2004b; Hagiwara et al., 2005; Khimich et al., 2005; Juranek et al., 2006; Siksou et al., 2007; Limbach et al., 2011; Nishimune, 2012).

The identification and molecular characterization of interacting partners revealed that Piccolo and Bassoon use their multi-domain structure to contribute to various features of presynaptic function (Table 1, Figure 1D). These include assembly of AZ scaffolds, organization of neurotransmitter release machinery, linkage of actin dynamics and endocytosis, maintenance of synapse integrity as well as integration of signaling pathways and synapto-nuclear signaling.

\section{SCAFFOLDING AND ASSEMBLY OF ACTIVE ZONES}

The assembly of presynaptic AZs starts at the trans-Golgi network, where components are recruited into precursor vesicles and delivered to nascent synapses (Ahmari et al., 2000; Zhai et al., 2001; Garner et al., 2002; Shapira et al., 2003; Tao-Cheng, 2007; Fairless et al., 2008; Bury and Sabo, 2011; Maas et al., 2012). Although it was initially thought that $\mathrm{AZ}$ proteins were pre-assembled on a single precursor vesicle (Ahmari et al., 2000; Zhai et al., 2001; Shapira et al., 2003), more recent studies argue for the existence of at least three types of precursor vesicles that carry complexes between Piccolo-Bassoon-ELKS/CAST, RIM-Neurexin-CASKvoltage-gated $\mathrm{Ca}^{2+}$ channels (VGCCs) or Munc13 (Tao-Cheng, 2007; Fairless et al., 2008; Maas et al., 2012). Intriguingly, the assembly of Piccolo-Bassoon-ELKS/CAST transport vesicles (PTV) not only depends on Piccolo and Bassoon, but also on their ability to interact with Golgi-membranes, ELKS/CAST and the membrane fission protein CtBP1/BARS (Dresbach et al., 2003, 2006; Maas et al., 2012). The trafficking and delivery of PTVs to nascent and mature synapses utilizes microtubule-based transport (Fejtova et al., 2009; Bury and Sabo, 2011; Maas et al., 2012) and the activities of anterograde and retrograde motors. Here, attachment to the retrograde motor dynein is mediated by the direct interaction of Bassoon with dynein-light chains (Dlc1/2; Fejtova et al., 2009). Kinesins are also involved and require the adaptor protein Syntabulin, though the linkage to PTVs is currently unknown (Cai et al., 2007).

Once delivered to nascent synapses, the core AZ complex assembles in response to transsynaptic signals from adhesion molecules such as Neurexins and Neuroligins (Waites et al., 2005; Siddiqui and Craig, 2011), occurring within minutes of initial axo-dendritic contact (Vardinon-Friedman et al., 2000; Garner et al., 2002; Lucido et al., 2009). The organization of this complex is determined by a series of protein-protein interactions between Munc13, RIM, Liprin- $\alpha$, ELKS/CAST, RBP, Bassoon and Piccolo (see Ackermann et al., 2015). From the Bassoon-Piccolo perspective, this can be mediated via domains that promote interactions between Piccolo-Bassoon (coiled-coil region 2, CC2), Bassoon-Piccolo-ELKS/CAST and/or Munc13 (CC3), Piccolo-RIM (C2A domain) or Bassoon-RBPs (Figure 1; Table 1). These are complemented by interactions between Munc13, RIM, ELKS/CAST, Liprin- $\alpha$ and RBPs (Wang et al., 2009; Gundelfinger and Fejtova, 2012; Südhof, 2012). Together, this scaffold is thought to create a platform for integrating other key features of the CAZ.

Importantly, loss of function studies of Bassoon or Piccolo have not been shown to affect the ultra-structural organization of presynaptic AZs of central synapses (Altrock et al., 2003; Leal-Ortiz et al., 2008; Mukherjee et al., 2010), perhaps due to structural redundancy between these and/or other CAZ proteins. Notable exceptions have been observed at vertebrate sensory synapses. Here, loss of Bassoon disrupts the attachment of synaptic ribbons to the arciform density at retinal photoreceptor terminals and at auditory inner hair cell synapses (Dick et al., 2003; Khimich et al., 2005; tom Dieck et al., 2005). At these synapses, Bassoon appears to utilize its interactions with Ribeye and ELKS/CAST (Table 1) to tether ribbons to the AZ (TakaoRikitsu et al., 2004; tom Dieck et al., 2005; Magupalli et al., 2008). Conversely, loss of the main Piccolo isoform (Piccolino) from mouse photoreceptor cells alters the maturation and ultrastructure of ribbons, i.e., their transition from spherical to ribbon shape structures (Regus-Leidig et al., 2013, 2014).

\section{EXOCYTOSIS AND LOCALIZATION OF VOLTAGE-GATED $\mathrm{CA}^{2+}$ CHANNELS}

A core function of presynaptic AZs is the regulated release of neurotransmitters, a process which involves the tethering, docking, priming and fusion of SVs with the AZ plasma membrane in a calcium-dependent manner (Südhof, 2012). This requires a delicate interplay between RIMs, Munc13s, SNARE complexes, synaptotagmin and VGCCs. Recent studies on synapses lacking Bassoon indicate a role for this CAZ protein in the recruitment of SVs into vacated release sites as well as the positioning of VGCC near release sites, i.e., positional priming (Frank et al., 2010; Hallermann et al., 2010; Jing et al., 2013; Mendoza Schulz et al., 2014). Regarding the latter, Bassoon, similar to RIMs, has been found to bind RBPs-molecules known to associate with VGCCs (Hibino et al., 2002). In contrast to RIM $\alpha$-isoforms, which appear to use RBPs to tether various types of VGCCs (e.g., $\mathrm{Ca}_{V} 2.2$ or $\mathrm{N}$-, and $\mathrm{Ca}_{\mathrm{V}} 2.1$ or P/Qtypes) to AZs (Han et al., 2011; Gundelfinger and Fejtova, 2012; Kaeser et al., 2012), Bassoon selectively positions P/Qtype channels near SV release sites of hippocampal synapses (Davydova et al., 2014). At present, it is unclear why different protein interactions are used to tether VGCC into the AZs. One explanation is that it allows synapses to have functional diversity and/or plasticity. For example, $\mathrm{N}$ - and P/Q-type channels have been linked to immature and mature synapses, respectively (Scholz and Miller, 1995). Theoretically, the loss of Bassoon 


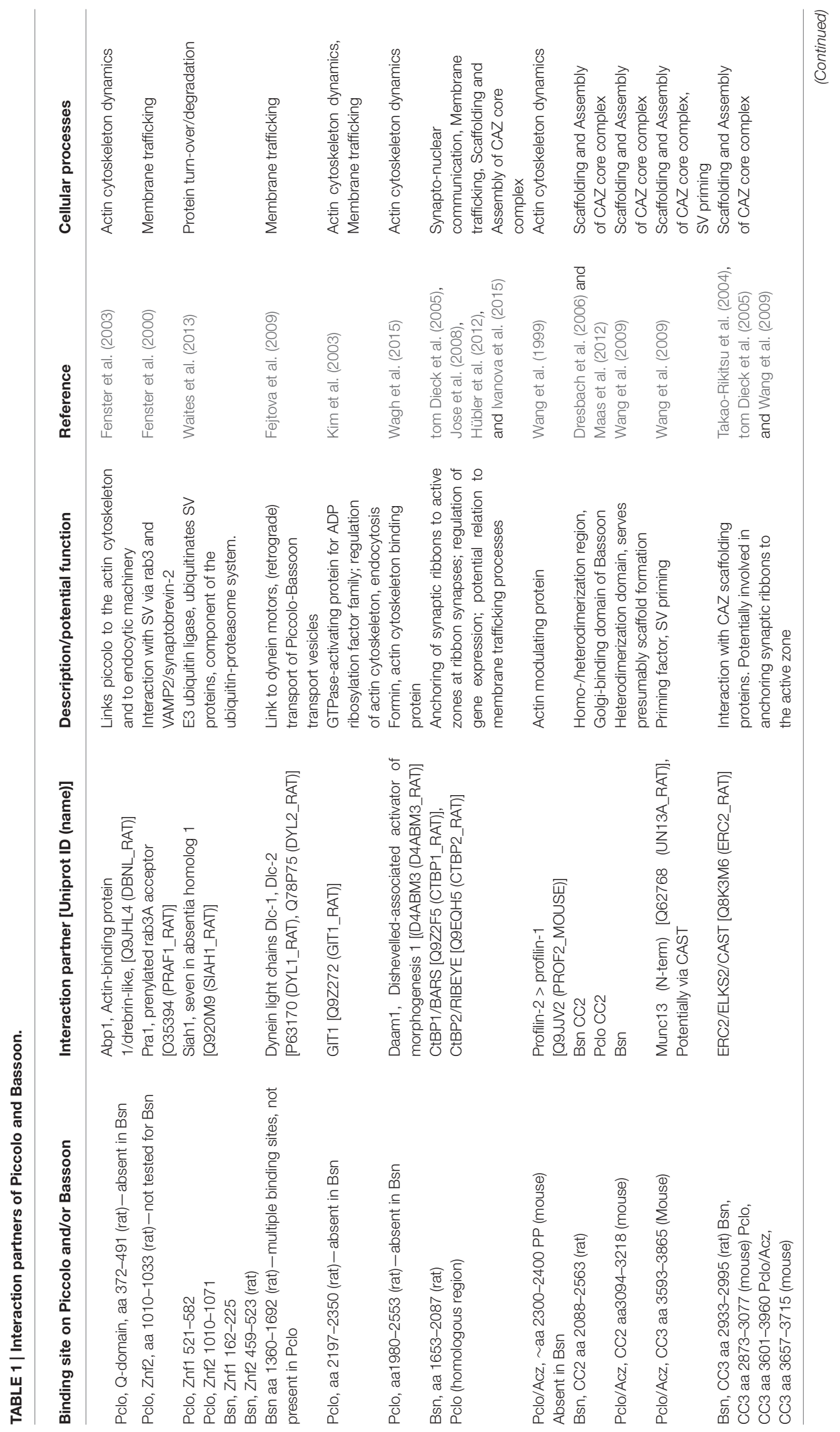




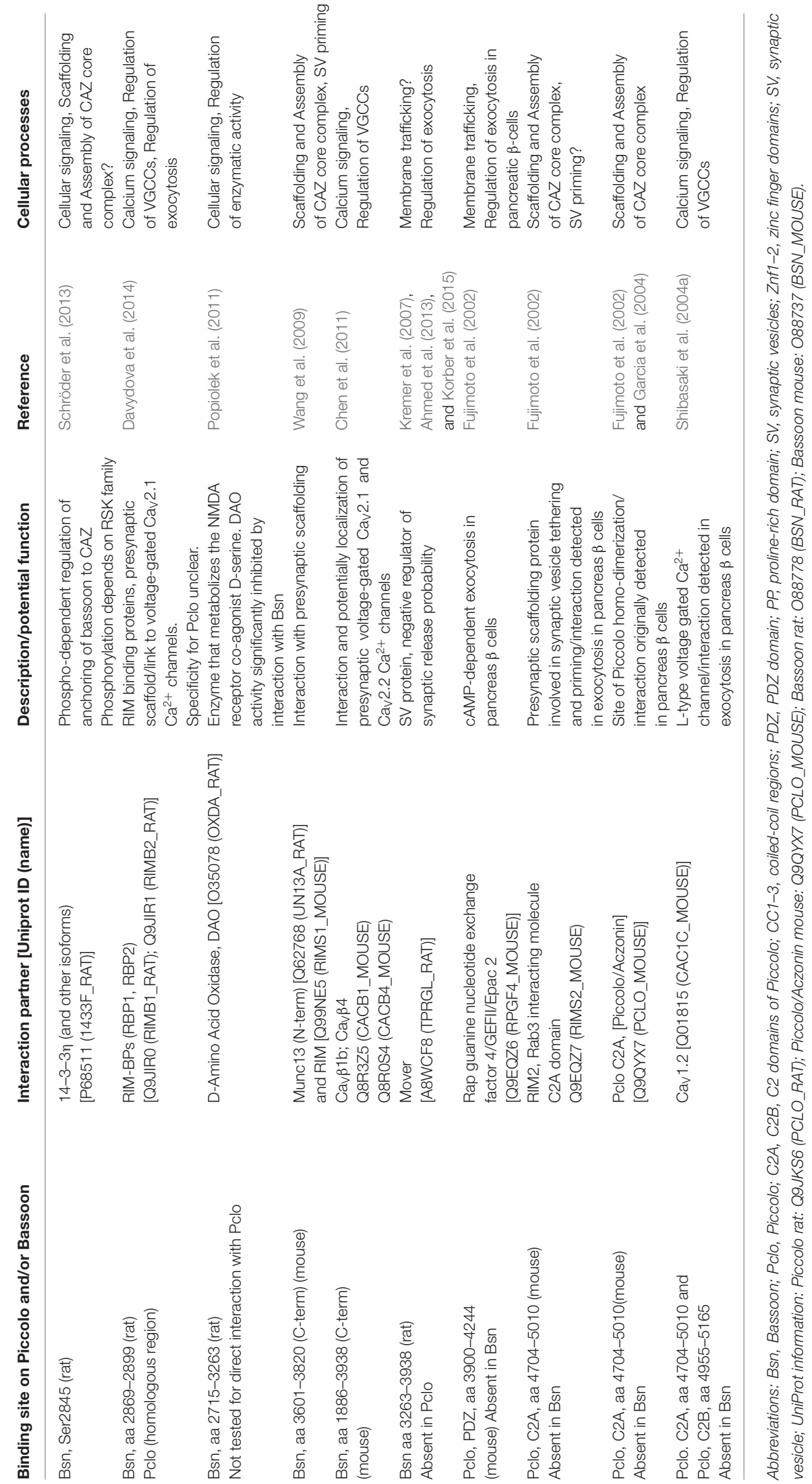


and thus P/Q type channels could result in more immature synapses. Based on our present knowledge one can hypothesize that RIM $\alpha$-isoforms are the key regulators for VGCC recruitment into the AZ, while Bassoon seems to be involved in more subtle subtype-specific regulation of positional priming events at various types of brain synapses (Südhof, 2012; Davydova et al., 2014).

At inner ear hair cell ribbon synapses, Bassoon also contributes to the appropriate localization of L-type VGCC (Cav 1.3). $\mathrm{Ca}^{2+}$ influx and $\mathrm{Ca}_{V} 1.3$ density is reduced in Bassoon (Bsn)-mutant mice (Khimich et al., 2005; Frank et al., 2010). This phenotype can be partly attributed directly to Bassoon function, but is enhanced by the lack of ribbon anchoring due to loss of Bassoon (Jing et al., 2013).

For the vertebrate neuromuscular junction, the C-terminal third of Bassoon has been shown to interact with $\beta 1 b$ and $\beta 4$ VGCC subunits suggesting an involvement of these interactions in the recruitment, localization and regulation of presynaptic calcium channels (Chen et al., 2011; Nishimune et al., 2012). Additional evidence for an interaction between VGCC and Piccolo and/or Bassoon derives from the proteomic analysis of calcium channel complexes both in the CNS (Müller et al., 2010) and at the neuromuscular junction (Carlson et al., 2010).

In contrast to Bassoon, a functional link between Piccolo and the localization of VGCC at brain synapses is less well explored. Here, one point of focus with respect to the regulated neurotransmitter release has been on its C2A domain. Similar to other $\mathrm{C} 2 \mathrm{~A}$ domains, this region in Piccolo binds calcium (albeit with low affinity) and induces a conformational change in this domain (Gerber et al., 2001; Garcia et al., 2004) that affects its association with phospholipids and its dimerization. However, no effect on synaptic transmission was observed if mutations that disrupt calcium binding were knocked into the C2A domain in the Piccolo (Pclo) gene (Mukherjee et al., 2010), leaving open the role of the C2A domain in CNS synapse function. Intriguingly, the Piccolo $\mathrm{C} 2 \mathrm{~A}$ domain has been reported to regulate the surface levels of dopamine transporters (DAT; Cen et al., 2008), and when over-expressed in transgenic mice to induce depression-like behaviors (FurukawaHibi et al., 2010), implying a role for Piccolo in dopaminergic transmission. Consistently, a genome wide association study identified a mutation in the $\mathrm{C} 2 \mathrm{~A}$ domain of Piccolo in patients with major depressive disorders (Giniatullina et al., 2015), though how this mutation causes depression remains unclear.

Other insights into Piccolo's role in regulated secretion have come from experiments on $\beta$-islet cells. Here, the C2A domain was found to bind RIM2 and L-type VGCC ( $\left.\mathrm{Ca}_{V} 1.2\right)$. Moreover, Piccolo can interact with the cAMP-sensor Epac2 (Rap guanine nucleotide exchange factor 4 or cAMP-GEFI; see Table 1) and loss of Piccolo function was found to impair cAMP-dependent insulin secretion (Fujimoto et al., 2002; Shibasaki et al., 2004a; Jacobo et al., 2009).

Bassoon and Piccolo seem to have functions in organizing the neurotransmitter release machinery including the tethering and priming of SVs at AZs. Thus both proteins participate in the formation of the CAZ core complex that recruits factors essential for tethering and priming of SVs, such as Munc13s and RIM1/2 $\alpha$ isoforms (Wang et al., 2009; Table 1). Upon over-expression, the Piccolo/Aczonin CC3 region is targeted to nerve terminals and impairs SV recycling similar to the over-expression of the RIM1 zinc finger ( $\mathrm{Znf}$ ) domain. In addition the C-terminus of Bassoon can interact with the $\mathrm{N}$-terminal C2A domain in Munc13 (Wang et al., 2009). It is thus conceivable that this complex interplay might contribute to the regulation of RIM-dependent activation of Munc13 priming functions (Deng et al., 2011; Han et al., 2011; Südhof, 2012).

Mover, a SV-associated phospho-protein, was originally identified as a binding partner for Bassoon (Kremer et al., 2007; Ahmed et al., 2013) and recently characterized as a negative regulator of evoked SV exocytosis (Korber et al., 2015). ShRNAmediated knock-down of the protein in the Calyx of Held leads to an accelerated and enhanced synaptic depression caused by an increased sensitivity of the release apparatus to $\mathrm{Ca}^{2+}$. The role of Bassoon in this context is yet unclear, as a similar synaptic depression phenotypes have not been observed in Bsn-mutant mice (Altrock et al., 2003).

Indirect evidence that Bassoon may also be involved in the release of brain-derived neurotrophic factor (BDNF) from large dense-core vesicles comes from the investigation of Bsnmutant mice. Accumulation of high amounts of BDNF, in particular brain regions including hippocampus, cerebral cortex and striatum, has been observed in mutant brains (Ghiglieri et al., 2010; Heyden et al., 2011; Dieni et al., 2012, 2015).

\section{ACTIN DYNAMICS AND ENDOCYTOSIS}

While Piccolo and Bassoon share a great deal of structural homology, each also contains unique segments, implying divergent functions. Studies of Piccolo have shown that it is selectively required for activity-induced F-actin assembly within presynaptic boutons and efficient synaptic transmission (Waites et al., 2011). Consistent with this concept, Piccolo, but not Bassoon, contains regions that interact with a variety of actinassociated proteins (Figure 1D; Table 1). These include Abp1 (Fenster et al., 2003), GIT1 (Kim et al., 2003), Daam1 (Wagh et al., 2015), Profilin2 (Wang et al., 1999; Waites et al., 2011) and Epac2 (Fujimoto et al., 2002). Functionally, these interactions appear to contribute to the regulated delivery and recycling of SVs within nerve terminals. For example, emerging evidence indicate that Profilin2, GIT1 and Daam1 may contribute to the polymerization of linear rather than branched F-actin filaments from AZs (Wagh et al., 2015), thought to be involved in the translocation of SVs from the reserve into the readily releasable pools. In this regard, Piccolo seems to act as a platform for the polymerization of these filaments via a region situated between CC1 and CC2 (Wagh et al., 2015). This region binds to GIT1, a GTPase-activating protein (GAP) for ADP-ribosylation factors (ARFs), involved in the regulation of membrane trafficking (Chavrier and Goud, 1999), as well as PIX1, a focal adhesion kinase, and Paxillin, both of which regulate the assembly of the actin cytoskeleton at focal adhesion site (Kim et al., 2003). This region also binds Daam1, a member of the formin family of molecules that directly polymerize 
actin upon activation by RhoA and/or the Wnt/Disheveled signaling complex (Habas et al., 2001; Liu et al., 2008) and Profilin2, an ADP/ATP nucleotide exchange factor for G-actin (Kovar, 2006), that binds at the mouth of formins, allowing for the rapid processive assembly of linear F-actin polymer (Higgs, 2005). Importantly, Daam1 only binds Piccolo and promotes F-actin assembly after activation, implying that Piccolo spatially controls the assembly of these filaments radial out from the AZ.

Intriguingly, two of these Piccolo binding partners, Abp1 and GIT1 are also linked to SV endocytosis (Fenster et al., 2003; Kim et al., 2003). For example, the actin-binding protein, Abp1 has been shown to interact the endocytic protein Dynamin (Kessels et al., 2001), while GIT1 directly associates with Stonin2, an endocytic adaptor protein (Podufall et al., 2014). In flies, SV recycling is impaired at synapses lacking GIT1 and is associated with the displacement of Stonin2/StonedB away from AZ implying that GIT1, and possibly Piccolo in vertebrates, help to couple exo- and endocytosis by creating a bridge between active and endocytic zones (Podufall et al., 2014). Of note, ultrafast endocytosis and bulk endocytosis both require the dynamic assembly of F-actin (Akbergenova and Bykhovskaia, 2009; Nguyen et al., 2012; Watanabe et al., 2013a,b), a process that could be facilitated via complexes between Piccolo, GIT1, Abp1 and other F-actin assembly proteins at endocytic sites.

\section{SYNAPSE MAINTENANCE AND INTEGRITY}

In addition to their roles in the structural and functional assembly of presynaptic AZs, Piccolo and Bassoon are involved in the maintenance of SV pools (Mukherjee et al., 2010) and act as regulators of presynaptic proteostasis and the integrity of synapses as observed upon knock-down of the proteins in primary neuronal culture (Waites et al., 2013). This new functionalities were only revealed at synapses lacking both proteins implying that it involves structurally conserved regions between these molecules. In this regard, there seem to be three mechanisms that contribute to the stability and integrity of presynaptic AZs. The first involves the dynamic exchange of synaptic proteins, which occurs on the order of tens of minutes to hours (Minerbi et al., 2009; Ziv and Fisher-Lavie, 2014); the second one the activity-dependent reorganization of AZs, which modulate the efficiency of neurotransmitter release (Lazarevic et al., 2011, 2013); and the third one the turnover/degradation of synaptic proteins, most of which have half-lives of 2-7 days (Cohen et al., 2013). Regarding the latter, Piccolo and Bassoon appear to play fundamental roles in regulating the ubiquitin-proteasome (UPS) and autophagy-lysosomal systems within presynaptic boutons (Waites et al., 2013). Specifically, it was observed that, in boutons lacking these AZ molecules, SV pools and synaptic junctions were lost. Moreover, ubiquitinated proteins, pleomorphic vesicles, and multi-vesicular bodies were observed to accumulate within these degenerating boutons, a process that required the activation of the UPS, lysosomal and ubiquitin systems. Thus far one molecular link between Piccolo and Bassoon and these degradative systems has been identified, i.e., Siah1 (Waites et al., 2013). Siah1 is an E3 ubiquitin ligase involved in the poly-ubiquitination of SV proteins such as synaptophysin and synuclein. Importantly, Siah1 binding to the Znf domains of Bassoon and Piccolo inhibits its activity (Waites et al., 2013). The functional importance of this locally regulated degradative system is unclear. Possibilities include the regulated release of neurotransmitter, the recycling of SVs and/or the removal of misfolded or aging proteins (Waites and Garner, 2011; Ackermann et al., 2015).

\section{PRESYNAPSE-TO-NUCLEUS SIGNALING}

Communication between synapses and the soma, in particular the nucleus, of a neuron is essential for neuronal survival as well as for processes of homeostatic and associative plasticity. While multiple synapto-nuclear signaling pathways have been reported for the postsynapse (for review, see Jordan and Kreutz, 2009; Panayotis et al., 2015), much less is understood about presynapse to nucleus communication. Known pathways from the presynapse or the axon to the nucleus include retrograde signaling of neurotrophins via signaling endosomes (Cosker and Segal, 2014) and retrograde signal transduction from sites of injury (Panayotis et al., 2015). One recently discovered signaling pathway involves Bassoon and Piccolo as synaptic key regulators for presynaptic recruitment and release of the transcriptional co-repressor CtBP1 (aka BARS; Ivanova et al., 2015). The interaction between Bassoon or Piccolo and CtBP1 is mediated by the metabolic sensor system $\mathrm{NAD}^{+} / \mathrm{NADH}$ and contributes to activity-dependent distribution of CtBP1 between presynapses and the nucleus. High activity shifts the equilibrium between synaptic and nuclear CtBP1 pools to synapses, low activity to the nucleus (Ivanova et al., 2015; Kravchick and Jordan, 2015). CtBP1 (as its paralogue CtBP2) is involved both gene-specific and global repression of gene transcription and has been implicated in processes of development and tumorigenesis (Chinnadurai, 2007). By controlling the synapto-nuclear distribution of CtBPs, Bassoon and Piccolo contribute significantly to the adjustment of activity-regulated gene expression and in turn to processes of long-term implementation of memories.

Of note, the interaction of CtBPs with Bassoon and Piccolo has long been known (tom Dieck et al., 2005; Jose et al., 2008; Hübler et al., 2012). Because of its functional involvement in dynamin-independent fission events, such as budding of vesicles from trans-Golgi membranes, macropinocytosis or fluidphase endocytosis (Corda et al., 2006; Valente et al., 2013) the interaction may play also a role in membrane trafficking events within the presynapse and from the Golgi to the synapse (e.g., Maas et al., 2012). Moreover, as mentioned above, Bassoon's interaction with an N-terminally extended isoform of CtBP2, i.e., Ribeye (Schmitz et al., 2000), plays an important role in the assembly and anchoring of synaptic ribbons to their AZs in retinal photoreceptors and inner ear hair cells (Khimich et al., 2005; tom Dieck et al., 2005; Magupalli et al., 2008). An important question is how CtBPs act in so many different cellular functions? One simple concept is that it works together with different scaffold proteins such as Bassoon and Piccolo to direct its activity as an NAD/NADH sensor to control vesicular membrane fission, synaptic ribbon assembly and nuclear gene expression. 


\section{CONCLUSIONS}

The detailed analysis of protein binding partners for Piccolo and Bassoon support the concept that they are fundamentally involved in scaffolding a large number of proteins involved with various aspect of presynaptic function within AZs. State of the art in silico analysis of their structure (Figure 1D) reveals that individual subdomains of these molecules are likely organized into larger modules, which might facilitate the assembly of supera-molecular complexes devoted to specific $\mathrm{AZ}$ functions. For example, the C-terminal halves of both molecules seem to organize proteins involved in the docking, molecular priming and positional priming of SVs. Conversely the central regions of these molecules possess modules that have acquired unique functions, e.g., devoted to the dynamic assembly of actin and endocytosis vs. vesicular transport for Piccolo and Bassoon, respectively. Clearly the relevance of these super-modules needs to be explored further. Finally, although not discussed here, the functional relevance of the large number of posttranslational modifications (phosphorylation,

\section{REFERENCES}

Ackermann, F., Waites, C. L., and Garner, C. C. (2015). Presynaptic active zones in invertebrates and vertebrates. EMBO Rep. 16, 923-938. doi: 10.15252/embr. 201540434

Ahmari, S. E., Buchanan, J., and Smith, S. J. (2000). Assembly of presynaptic active zones from cytoplasmic transport packets. Nat. Neurosci. 3, 445-451. doi: 10. $1038 / 74814$

Ahmed, S., Wittenmayer, N., Kremer, T., Hoeber, J., Kiran Akula, A., Urlaub, H., et al. (2013). Mover is a homomeric phospho-protein present on synaptic vesicles. PLoS One 8:e63474. doi: 10.1371/journal.pone.0063474

Akbergenova, Y., and Bykhovskaia, M. (2009). Enhancement of the endosomal endocytic pathway increases quantal size. Mol. Cell. Neurosci. 40, 199-206. doi: 10.1016/j.mcn.2008.10.005

Altrock, W. D., Tom Dieck, S., Sokolov, M., Meyer, A. C., Sigler, A., Brakebusch, C., et al. (2003). Functional inactivation of a fraction of excitatory synapses in mice deficient for the active zone protein bassoon. Neuron 37, 787-800. doi: 10 . 1016/s0896-6273(03)00088-6

Berman, H. M., Westbrook, J., Feng, Z., Gilliland, G., Bhat, T. N., Weissig, H., et al. (2000). The protein data bank. Nucleic Acids Res. 28, 235-242. doi: 10. 1093/nar/28.1.235

Brandstatter, J. H., Fletcher, E. L., Garner, C. C., Gundelfinger, E. D., and Wassle, H. (1999). Differential expression of the presynaptic cytomatrix protein bassoon among ribbon synapses in the mammalian retina. Eur. J. Neurosci. 11, 3683-3693. doi: 10.1046/j.1460-9568.1999.00793.x

Bruckner, J. J., Gratz, S. J., Slind, J. K., Geske, R. R., Cummings, A. M., Galindo, S. E., et al. (2012). Fife, a Drosophila Piccolo-RIM homolog, promotes active zone organization and neurotransmitter release. J. Neurosci. 32, 17048-17058. doi: 10.1523/JNEUROSCI.3267-12.2012

Bury, L. A., and Sabo, S. L. (2011). Coordinated trafficking of synaptic vesicle and active zone proteins prior to synapse formation. Neural Dev. 6:24. doi: 10 . 1186/1749-8104-6-24

Cai, Q., Pan, P. Y., and Sheng, Z. H. (2007). Syntabulin-kinesin-1 family member 5B-mediated axonal transport contributes to activity-dependent presynaptic assembly. J. Neurosci. 27, 7284-7296. doi: 10.1523/jneurosci.0731-07.2007

Carlson, S. S., Valdez, G., and Sanes, J. R. (2010). Presynaptic calcium channels and alpha3-integrins are complexed with synaptic cleft laminins, cytoskeletal elements and active zone components. J. Neurochem. 115, 654-666. doi: 10. 1111/j.1471-4159.2010.06965.x

Cases-Langhoff, C., Voss, B., Garner, A. M., Appeltauer, U., Takei, K., Kindler, S., et al. (1996). Piccolo, a novel $420 \mathrm{kDa}$ protein associated with the presynaptic cytomatrix. Eur. J. Cell Biol. 69, 214-223.
O-glycosylation, ubiquitination; Trinidad et al., 2006; Vosseller et al., 2006; Munton et al., 2007; Chalkley et al., 2009; Lazarevic et al., 2011; Schröder et al., 2013; Ackermann et al., 2015) has yet to be examined, though roles in the regulated rearrangement during learning-related plasticity of AZs are likely (e.g., Kähne et al., 2012).

\section{AUTHOR CONTRIBUTIONS}

EDG and CCG have written the article. CR contributed essential discussions and designed Figure 1D.

\section{ACKNOWLEDGMENTS}

Work in the authors' laboratories has been supported by the DFG (including SFB665, SFB779, SFB854, SFB958), the European Union, the Federal Government of Germany (BMBF), the State of Saxony-Anhalt, Leibniz SAW grants and the DZNE. We wish to thank Serge Marty and Antoine Triller for permission to reuse the electron micrograph in Figure 1A.

Cen, X., Nitta, A., Ibi, D., Zhao, Y., Niwa, M., Taguchi, K., et al. (2008) Identification of Piccolo as a regulator of behavioral plasticity and dopamine transporter internalization. Mol. Psychiatry 13, 451-463. doi: 10.1038/sj.mp. 4002132

Chalkley, R. J., Thalhammer, A., Schoepfer, R., and Burlingame, A. L. (2009). Identification of protein O-GlcNAcylation sites using electron transfer dissociation mass spectrometry on native peptides. Proc. Natl. Acad. Sci. U S A 106, 8894-8899. doi: 10.1073/pnas.0900288106

Chavrier, P., and Goud, B. (1999). The role of ARF and Rab GTPases in membrane transport. Curr. Opin. Cell Biol. 11, 466-475. doi: 10.1016/s09550674(99)80067-2

Chen, J., Billings, S. E., and Nishimune, H. (2011). Calcium channels link the muscle-derived synapse organizer laminin beta2 to Bassoon and CAST/Erc2 to organize presynaptic active zones. J. Neurosci. 31, 512-525. doi: 10 1523/JNEUROSCI.3771-10.2011

Chinnadurai, G. (2007). Transcriptional regulation by C-terminal binding proteins. Int. J. Biochem. Cell Biol. 39, 1593-1607. doi: 10.1016/j.biocel.2007. 01.025

Cohen, L. D., Zuchman, R., Sorokina, O., Müller, A., Dieterich, D. C., Armstrong, J. D., et al. (2013). Metabolic turnover of synaptic proteins: kinetics, interdependencies and implications for synaptic maintenance. PLoS One 8:e63191. doi: 10.1371/journal.pone.0063191

Corda, D., Colanzi, A., and Luini, A. (2006). The multiple activities of CtBP/BARS proteins: the Golgi view. Trends Cell Biol. 16, 167-173. doi: 10.1016/j.tcb.2006. 01.007

Cosker, K. E., and Segal, R. A. (2014). Neuronal signaling through endocytosis. Cold Spring Harb Perspect. Biol. 6:a020669. doi: 10.1101/cshperspect.a020669

Davydova, D., Marini, C., King, C., Klueva, J., Bischof, F., Romorini, S., et al. (2014). Bassoon specifically controls presynaptic P/Q-type $\mathrm{Ca}(2+)$ channels via RIM-binding protein. Neuron 82, 181-194. doi: 10.1016/j.neuron.2014.02.012

Deng, L., Kaeser, P. S., Xu, W., and Südhof, T. C. (2011). RIM proteins activate vesicle priming by reversing autoinhibitory Homodimerization of Munc13. Neuron 69, 317-331. doi: 10.1016/j.neuron.2011.01.005

Dick, O., Hack, I., Altrock, W. D., Garner, C. C., Gundelfinger, E. D., and Brandstätter, J. H. (2001). Localization of the presynaptic cytomatrix protein Piccolo at ribbon and conventional synapses in the rat retina: comparison with Bassoon. J. Comp. Neurol. 439, 224-234. doi: 10.1002/cne. 1344

Dick, O., Tom Dieck, S., Altrock, W. D., Ammermuller, J., Weiler, R., Garner, C. C., et al. (2003). The presynaptic active zone protein bassoon is essential for photoreceptor ribbon synapse formation in the retina. Neuron 37, 775-786. doi: 10.1016/s0896-6273(03)00086-2 
Dieni, S., Matsumoto, T., Dekkers, M., Rauskolb, S., Ionescu, M. S., Deogracias, R., et al. (2012). BDNF and its pro-peptide are stored in presynaptic dense core vesicles in brain neurons. J. Cell Biol. 196, 775-788. doi: 10.1083/jcb.201201038

Dieni, S., Nestel, S., Sibbe, M., Frotscher, M., and Hellwig, S. (2015). Distinct synaptic and neurochemical changes to the granule cell-CA3 projection in Bassoon mutant mice. Front. Synaptic Neurosci. 7:18. doi: 10.3389/fnsyn.2015. 00018

Dresbach, T., Hempelmann, A., Spilker, C., Tom Dieck, S., Altrock, W. D., Zuschratter, W., et al. (2003). Functional regions of the presynaptic cytomatrix protein bassoon: significance for synaptic targeting and cytomatrix anchoring. Mol. Cell. Neurosci. 23, 279-291. doi: 10.1016/s1044-7431(03)00015-0

Dresbach, T., Torres, V., Wittenmayer, N., Altrock, W. D., Zamorano, P., Zuschratter, W., et al. (2006). Assembly of active zone precursor vesicles: obligatory trafficking of presynaptic cytomatrix proteins Bassoon and Piccolo via a trans-Golgi compartment. J. Biol. Chem. 281, 6038-6047. doi: 10.1074/jbc. m508784200

Fairless, R., Masius, H., Rohlmann, A., Heupel, K., Ahmad, M., Reissner, C., et al. (2008). Polarized targeting of neurexins to synapses is regulated by their Cterminal sequences. J. Neurosci. 28, 12969-12981. doi: 10.1523/JNEUROSCI. 5294-07.2008

Fejtova, A., Davydova, D., Bischof, F., Lazarevic, V., Altrock, W. D., Romorini, S., et al. (2009). Dynein light chain regulates axonal trafficking and synaptic levels of Bassoon. J. Cell Biol. 185, 341-355. doi: 10.1083/jcb.2008 07155

Fenster, S. D., Chung, W. J., Zhai, R., Cases-Langhoff, C., Voss, B., Garner, A. M., et al. (2000). Piccolo, a presynaptic zinc finger protein structurally related to bassoon. Neuron 25, 203-214. doi: 10.1016/s0896-6273(00)80883-1

Fenster, S. D., Kessels, M. M., Qualmann, B., Chung, W. J., Nash, J., Gundelfinger, E. D., et al. (2003). Interactions between Piccolo and the actin/dynaminbinding protein Abp1 link vesicle endocytosis to presynaptic active zones. J. Biol. Chem. 278, 20268-20277. doi: 10.1074/jbc.m210792200

Frank, T., Rutherford, M. A., Strenzke, N., Neef, A., Pangršič, T., Khimich, D., et al. (2010). Bassoon and the synaptic ribbon organize $\mathrm{Ca}(2)+$ channels and vesicles to add release sites and promote refilling. Neuron 68, 724-738. doi: 10.1016/j. neuron.2010.10.027

Fujimoto, K., Shibasaki, T., Yokoi, N., Kashima, Y., Matsumoto, M., Sasaki, T., et al. (2002). Piccolo, a $\mathrm{Ca}^{2+}$ sensor in pancreatic beta-cells. Involvement of cAMP-GEFII.Rim2.Piccolo complex in cAMP-dependent exocytosis. J. Biol. Chem. 277, 50497-50502. doi: 10.1074/jbc.m210146200

Furukawa-Hibi, Y., Nitta, A., Fukumitsu, H., Somiya, H., Furukawa, S., Nabeshima, T., et al. (2010). Overexpression of piccolo C2A domain induces depression-like behavior in mice. Neuroreport 21, 1177-1181. doi: 10 . 1097/WNR.0b013e3283411685

Garcia, J., Gerber, S. H., Sugita, S., Südhof, T. C., and Rizo, J. (2004). A conformational switch in the Piccolo C2A domain regulated by alternative splicing. Nat. Struct. Mol. Biol. 11, 45-53. doi: 10.1038/nsmb707

Garner, C. C., Kindler, S., and Gundelfinger, E. D. (2000). Molecular determinants of presynaptic active zones. Curr. Opin. Neurobiol. 10, 321-327. doi: 10. 1016/s0959-4388(00)00093-3

Garner, C. C., Zhai, R. G., Gundelfinger, E. D., and Ziv, N. E. (2002). Molecular mechanisms of CNS synaptogenesis. Trends Neurosci. 25, 243-251. doi: 10. 1016/s0166-2236(02)02152-5

Gerber, S. H., Garcia, J., Rizo, J., and Südhof, T. C. (2001). An unusual C(2)domain in the active-zone protein piccolo: implications for $\mathrm{Ca}(2+)$ regulation of neurotransmitter release. EMBO J. 20, 1605-1619. doi: 10.1093/emboj/20.7. 1605

Ghiglieri, V., Sgobio, C., Patassini, S., Bagetta, V., Fejtova, A., Giampà, C., et al. (2010). TrkB/BDNF-dependent striatal plasticity and behavior in a genetic model of epilepsy: modulation by valproic acid. Neuropsychopharmacology 35, 1531-1540. doi: 10.1038/npp.2010.23

Giniatullina, A., Maroteaux, G., Geerts, C. J., Koopmans, B., Loos, M., Klaassen, R., et al. (2015). Functional characterization of the PCLO p.Ser4814Ala variant associated with major depressive disorder reveals cellular but not behavioral differences. Neuroscience 300, 518-538. doi: 10.1016/j.neuroscience.2015. 05.047

Gruber, M., and Lupas, A. N. (2003). Historical review: another 50th anniversary-new periodicities in coiled coils. Trends Biochem. Sci. 28, 679-685. doi: 10.1016/j.tibs.2003.10.008
Gundelfinger, E. D., and Fejtova, A. (2012). Molecular organization and plasticity of the cytomatrix at the active zone. Curr. Opin. Neurobiol. 22, 423-430. doi: 10. 1016/j.conb.2011.10.005

Habas, R., Kato, Y., and He, X. (2001). Wnt/Frizzled activation of Rho regulates vertebrate gastrulation and requires a novel Formin homology protein Daam1. Cell 107, 843-854. doi: 10.1016/s0092-8674(01)00614-6

Haeberle, H., Fujiwara, M., Chuang, J., Medina, M. M., Panditrao, M. V., Bechstedt, S., et al. (2004). Molecular profiling reveals synaptic release machinery in Merkel cells. Proc. Natl. Acad. Sci. U S A 101, 14503-14508. doi: 10.1073/pnas.0406308101

Hagiwara, A., Fukazawa, Y., Deguchi-Tawarada, M., Ohtsuka, T., and Shigemoto, R. (2005). Differential distribution of release-related proteins in the hippocampal CA3 area as revealed by freeze-fracture replica labeling. J. Comp. Neurol. 489, 195-216. doi: 10.1002/cne.20633

Hallermann, S., Fejtova, A., Schmidt, H., Weyhersmüller, A., Silver, R. A., Gundelfinger, E. D., et al. (2010). Bassoon speeds vesicle reloading at a central excitatory synapse. Neuron 68, 710-723. doi: 10.1016/j.neuron.2010.10.026

Han, Y., Kaeser, P. S., Südhof, T. C., and Schneggenburger, R. (2011). RIM determines $\mathrm{Ca}(2+)$ channel density and vesicle docking at the presynaptic active zone. Neuron 69, 304-316. doi: 10.1016/j.neuron.2010.12.014

Heyden, A., Ionescu, M. C., Romorini, S., Kracht, B., Ghiglieri, V., Calabresi, P., et al. (2011). Hippocampal enlargement in Bassoon-mutant mice is associated with enhanced neurogenesis, reduced apoptosis and abnormal BDNF levels. Cell Tissue Res. 346, 11-26. doi: 10.1007/s00441-0111233-3

Hibino, H., Pironkova, R., Onwumere, O., Vologodskaia, M., Hudspeth, A. J., and Lesage, F. (2002). RIM binding proteins (RBPs) couple Rab3-interacting molecules (RIMs) to voltage-gated $\mathrm{Ca}(2+)$ channels. Neuron 34, 411-423. doi: 10.1016/s0896-6273(02)00667-0

Higgs, H. N. (2005). Formin proteins: a domain-based approach. Trends Biochem. Sci. 30, 342-353. doi: 10.1016/j.tibs.2005.04.014

Hübler, D., Rankovic, M., Richter, K., Lazarevic, V., Altrock, W. D., Fischer, K. D., et al. (2012). Differential spatial expression and subcellular localization of CtBP family members in rodent brain. PLoS One 7:e39710. doi: 10.1371/journal.pone. 0039710

Ivanova, D., Dirks, A., Montenegro-Venegas, C., Schone, C., Altrock, W. D., Marini, C., et al. (2015). Synaptic activity controls localization and function of CtBP1 via binding to Bassoon and Piccolo. EMBO J. 34, 1056-1077. doi: 10 15252/embj.201488796

Jacobo, S. M., Guerra, M. L., Jarrard, R. E., Przybyla, J. A., Liu, G., Watts, V. J., et al. (2009). The intracellular II-III loops of Cav1.2 and Cav1.3 uncouple Ltype voltage-gated $\mathrm{Ca}^{2+}$ channels from glucagon-like peptide-1 potentiation of insulin secretion in INS-1 cells via displacement from lipid rafts. J. Pharmacol. Exp. Ther. 330, 283-293. doi: 10.1124/jpet.109.150672

Jing, Z., Rutherford, M. A., Takago, H., Frank, T., Fejtova, A., Khimich, D., et al. (2013). Disruption of the presynaptic cytomatrix protein bassoon degrades ribbon anchorage, multiquantal release and sound encoding at the hair cell afferent synapse. J. Neurosci. 33, 4456-4467. doi: 10.1523/JNEUROSCI.349112.2013

Jordan, B. A., and Kreutz, M. R. (2009). Nucleocytoplasmic protein shuttling: the direct route in synapse-to-nucleus signaling. Trends Neurosci. 32, 392-401. doi: 10.1016/j.tins.2009.04.001

Jose, M., Nair, D. K., Altrock, W. D., Dresbach, T., Gundelfinger, E. D., and Zuschratter, W. (2008). Investigating interactions mediated by the presynaptic protein bassoon in living cells by Foerster's resonance energy transfer and fluorescence lifetime imaging microscopy. Biophys. J. 94, 1483-1496. doi: 10. 1529/biophysj.107.111674

Juranek, J., Mukherjee, K., Rickmann, M., Martens, H., Calka, J., Südhof, T. C., et al. (2006). Differential expression of active zone proteins in neuromuscular junctions suggests functional diversification. Eur. J. Neurosci. 24, 3043-3052. doi: 10.1111/j.1460-9568.2006.05183.x

Kaeser, P. S., Deng, L., Fan, M., and Südhof, T. C. (2012). RIM genes differentially contribute to organizing presynaptic release sites. Proc. Natl. Acad. Sci. U S A 109, 11830-11835. doi: 10.1073/pnas.1209318109

Kähne, T., Kolodziej, A., Smalla, K. H., Eisenschmidt, E., Haus, U. U., Weismantel, R., et al. (2012). Synaptic proteome changes in mouse brain regions upon auditory discrimination learning. Proteomics 12, 2433-2444. doi: 10.1002/pmic. 201100669 
Kelley, L. A., and Sternberg, M. J. (2009). Protein structure prediction on the web: a case study using the Phyre server. Nat. Protoc. 4, 363-371. doi: 10.1038/nprot. 2009.2

Kessels, M. M., Engqvist-Goldstein, A. E., Drubin, D. G., and Qualmann, B. (2001). Mammalian Abp1, a signal-responsive F-actin-binding protein, links the actin cytoskeleton to endocytosis via the GTPase dynamin. J. Cell Biol. 153, 351-366. doi: $10.1083 /$ jcb.153.2.351

Khimich, D., Nouvian, R., Pujol, R., Tom Dieck, S., Egner, A., Gundelfinger, E. D., et al. (2005). Hair cell synaptic ribbons are essential for synchronous auditory signalling. Nature 434, 889-894. doi: 10.1038/nature03418

Kim, S., Ko, J., Shin, H., Lee, J. R., Lim, C., Han, J. H., et al. (2003). The GIT family of proteins forms multimers and associates with the presynaptic cytomatrix protein Piccolo. J. Biol. Chem. 278, 6291-6300. doi: 10.1074/jbc.m212287200

Korber, C., Horstmann, H., Venkataramani, V., Herrmannsdörfer, F., Kremer, T., Kaiser, M., et al. (2015). Modulation of presynaptic release probability by the vertebrate-specific protein mover. Neuron 87, 521-533. doi: 10.1016/j.neuron. 2015.07.001

Kovar, D. R. (2006). Molecular details of formin-mediated actin assembly. Curr. Opin. Cell Biol. 18, 11-17. doi: 10.1016/j.ceb.2005.12.011

Kravchick, D. O., and Jordan, B. A. (2015). Presynapses go nuclear! EMBO J. 34, 984-986. doi: 10.15252/embj.201591331

Kremer, T., Kempf, C., Wittenmayer, N., Nawrotzki, R., Kuner, T., Kirsch, J., et al. (2007). Mover is a novel vertebrate-specific presynaptic protein with differential distribution at subsets of CNS synapses. FEBS Lett. 581, 4727-4733. doi: 10.1016/j.febslet.2007.08.070

Langnaese, K., Seidenbecher, C., Wex, H., Seidel, B., Hartung, K., Appeltauer, U., et al. (1996). Protein components of a rat brain synaptic junctional protein preparation. Brain Res. Mol. Brain Res. 42, 118-122. doi: 10.1016/s0169$328 x(96) 00147-7$

Lazarevic, V., Pothula, S., Andres-Alonso, M., and Fejtova, A. (2013). Molecular mechanisms driving homeostatic plasticity of neurotransmitter release. Front. Cell. Neurosci. 7:244. doi: 10.3389/fncel.2013.00244

Lazarevic, V., Schöne, C., Heine, M., Gundelfinger, E. D., and Fejtova, A. (2011). Extensive remodeling of the presynaptic cytomatrix upon homeostatic adaptation to network activity silencing. J. Neurosci. 31, 10189-10200. doi: 10. 1523/JNEUROSCI.2088-11.2011

Leal-Ortiz, S., Waites, C. L., Terry-Lorenzo, R., Zamorano, P., Gundelfinger, E. D., and Garner, C. C. (2008). Piccolo modulation of synapsinla dynamics regulates synaptic vesicle exocytosis. J. Cell Biol. 181, 831-846. doi: 10.1083/jcb. 200711167

Limbach, C., Laue, M. M., Wang, X., Hu, B., Thiede, N., Hultqvist, G., et al. (2011). Molecular in situ topology of Aczonin/Piccolo and associated proteins at the mammalian neurotransmitter release site. Proc. Natl. Acad. Sci. U S A 108, E392-E401. doi: 10.1073/pnas.1101707108

Liu, W., Sato, A., Khadka, D., Bharti, R., Diaz, H., Runnels, L. W., et al. (2008). Mechanism of activation of the Formin protein Daam1. Proc. Natl. Acad. Sci. U S A 105, 210-215. doi: 10.1073/pnas.0707277105

Lucido, A. L., Suarez Sanchez, F., Thostrup, P., Kwiatkowski, A. V., Leal-Ortiz, S., Gopalakrishnan, G., et al. (2009). Rapid assembly of functional presynaptic boutons triggered by adhesive contacts. J. Neurosci. 29, 12449-12466. doi: 10. 1523/JNEUROSCI.1381-09.2009

Maas, C., Torres, V. I., Altrock, W. D., Leal-Ortiz, S., Wagh, D., Terry-Lorenzo, R. T., et al. (2012). Formation of Golgi-derived active zone precursor vesicles. J. Neurosci. 32, 11095-11108. doi: 10.1523/JNEUROSCI.0195-12.2012

Magupalli, V. G., Schwarz, K., Alpadi, K., Natarajan, S., Seigel, G. M., and Schmitz, F. (2008). Multiple RIBEYE-RIBEYE interactions create a dynamic scaffold for the formation of synaptic ribbons. J. Neurosci. 28, 7954-7967. doi: 10. 1523/JNEUROSCI.1964-08.2008

Mendoza Schulz, A., Jing, Z., Sánchez Caro, J. M., Wetzel, F., Dresbach, T., Strenzke, N., et al. (2014). Bassoon-disruption slows vesicle replenishment and induces homeostatic plasticity at a CNS synapse. EMBO J. 33, 512-527. doi: 10 . 1002/embj.201385887

Minerbi, A., Kahana, R., Goldfeld, L., Kaufman, M., Marom, S., and Ziv, N. E. (2009). Long-term relationships between synaptic tenacity, synaptic remodeling and network activity. PLoS Biol. 7:e1000136. doi: 10.1371/journal. pbio. 1000136

Mukherjee, K., Yang, X., Gerber, S. H., Kwon, H. B., Ho, A., Castillo, P. E., et al. (2010). Piccolo and bassoon maintain synaptic vesicle clustering without directly participating in vesicle exocytosis. Proc. Natl. Acad. Sci. U S A 107 , 6504-6509. doi: 10.1073/pnas.1002307107

Müller, C. S., Haupt, A., Bildl, W., Schindler, J., Knaus, H. G., Meissner, M., et al. (2010). Quantitative proteomics of the Cav2 channel nano-environments in the mammalian brain. Proc. Natl. Acad. Sci. U S A 107, 14950-14957. doi: 10. 1073/pnas.1005940107

Munton, R. P., Tweedie-Cullen, R., Livingstone-Zatchej, M., Weinandy, F., Waidelich, M., Longo, D., et al. (2007). Qualitative and quantitative analyses of protein phosphorylation in naive and stimulated mouse synaptosomal preparations. Mol. Cell. Proteomics 6, 283-293. doi: 10.1074/mcp.m600046mcp200

Nguyen, T. H., Maucort, G., Sullivan, R. K., Schenning, M., Lavidis, N. A., McCluskey, A., et al. (2012). Actin- and dynamin-dependent maturation of bulk endocytosis restores neurotransmission following synaptic depletion. PLoS One 7:e36913. doi: 10.1371/journal.pone.0036913

Nishimune, H. (2012). Active zones of mammalian neuromuscular junctions: formation, density and aging. Ann. N Y Acad. Sci. 1274, 24-32. doi: 10.1111/j. 1749-6632.2012.06836.x

Nishimune, H., Numata, T., Chen, J., Aoki, Y., Wang, Y., Starr, M. P., et al. (2012). Active zone protein Bassoon co-localizes with presynaptic calcium channel, modifies channel function and recovers from aging related loss by exercise. PLoS One 7:e38029. doi: 10.1371/journal.pone.0038029

Nishimune, H., Sanes, J. R., and Carlson, S. S. (2004). A synaptic laminin-calcium channel interaction organizes active zones in motor nerve terminals. Nature 432, 580-587. doi: 10.1038/nature03112

Panayotis, N., Karpova, A., Kreutz, M. R., and Fainzilber, M. (2015). Macromolecular transport in synapse to nucleus communication. Trends Neurosci. 38, 108-116. doi: 10.1016/j.tins.2014.12.001

Podufall, J., Tian, R., Knoche, E., Puchkov, D., Walter, A. M., Rosa, S., et al. (2014). A presynaptic role for the cytomatrix protein GIT in synaptic vesicle recycling. Cell Rep. 7, 1417-1425. doi: 10.1016/j.celrep.2014.04.051

Popiolek, M., Ross, J. F., Charych, E., Chanda, P., Gundelfinger, E. D., Moss, S. J., et al. (2011). D-amino acid oxidase activity is inhibited by an interaction with bassoon protein at the presynaptic active zone. J. Biol. Chem. 286, 28867-28875. doi: 10.1074/jbc.M111.262063

Quiroz, F. G., and Chilkoti, A. (2015). Sequence heuristics to encode phase behaviour in intrinsically disordered protein polymers. Nat. Mater. 14, 1164-1171. doi: 10.1038/nmat4418

Regus-Leidig, H., Fuchs, M., Löhner, M., Leist, S. R., Leal-Ortiz, S., Chiodo, V. A., et al. (2014). In vivo knockdown of Piccolino disrupts presynaptic ribbon morphology in mouse photoreceptor synapses. Front. Cell. Neurosci. 8:259. doi: $10.3389 /$ fncel.2014.00259

Regus-Leidig, H., Ott, C., Löhner, M., Atorf, J., Fuchs, M., Sedmak, T., et al. (2013). Identification and immunocytochemical characterization of Piccolino, a novel Piccolo splice variant selectively expressed at sensory ribbon synapses of the eye and ear. PLoS One 8:e70373. doi: 10.1371/journal.pone. 0070373

Richter, K., Langnaese, K., Kreutz, M. R., Olias, G., Zhai, R., Scheich, H., et al. (1999). Presynaptic cytomatrix protein bassoon is localized at both excitatory and inhibitory synapses of rat brain. J. Comp. Neurol. 408, 437-448. doi: 10. 1002/(sici)1096-9861(19990607)408:3<437::aid-cne9>3.0.co;2-5

Rostaing, P., Real, E., Siksou, L., Lechaire, J. P., Boudier, T., Boeckers, T. M., et al. (2006). Analysis of synaptic ultrastructure without fixative using high-pressure freezing and tomography. Eur. J. Neurosci. 24, 3463-3474. doi: 10.1111/j.14609568.2006.05234.x

Sauder, J. M., and Dunbrack, R. L., Jr. (2000). Genomic fold assignment and rational modeling of proteins of biological interest. Proc. Int. Conf. Intell. Syst. Mol. Biol. 8, 296-306.

Schmitz, F., Königstorfer, A., and Südhof, T. C. (2000). RIBEYE, a component of synaptic ribbons: a protein's journey through evolution provides insight into synaptic ribbon function. Neuron 28, 857-872. doi: 10.1016/s08966273(00)00159-8

Schoch, S., and Gundelfinger, E. D. (2006). Molecular organization of the presynaptic active zone. Cell Tissue Res. 326, 379-391. doi: 10.1007/s00441-0060244-y

Scholz, K. P., and Miller, R. J. (1995). Developmental changes in presynaptic calcium channels coupled to glutamate release in cultured rat hippocampal neurons. J. Neurosci. 15, 4612-4617. 
Schröder, M. S., Stellmacher, A., Romorini, S., Marini, C., Montenegro-Venegas, C., Altrock, W. D., et al. (2013). Regulation of presynaptic anchoring of the scaffold protein Bassoon by phosphorylation-dependent interaction with 14-33 adaptor proteins. PLoS One 8:e58814. doi: 10.1371/journal.pone.0058814

Shapira, M., Zhai, R. G., Dresbach, T., Bresler, T., Torres, V. I., Gundelfinger, E. D., et al. (2003). Unitary assembly of presynaptic active zones from Piccolo-Bassoon transport vesicles. Neuron 38, 237-252. doi: 10.1016/s08966273(03)00207-1

Shibasaki, T., Sunaga, Y., Fujimoto, K., Kashima, Y., and Seino, S. (2004a). Interaction of ATP sensor, cAMP sensor, $\mathrm{Ca}^{2+}$ sensor and voltage-dependent $\mathrm{Ca}^{2+}$ channel in insulin granule exocytosis. J. Biol. Chem. 279, 7956-7961. doi: 10.1074/jbc.m309068200

Shibasaki, T., Sunaga, Y., and Seino, S. (2004b). Integration of ATP, cAMP and $\mathrm{Ca}^{2+}$ signals in insulin granule exocytosis. Diabetes 53, S59-S62. doi: 10. 2337/diabetes.53.suppl_3.s59

Siddiqui, T. J., and Craig, A. M. (2011). Synaptic organizing complexes. Curr. Opin. Neurobiol. 21, 132-143. doi: 10.1016/j.conb.2010.08.016

Sigrist, S. J., and Schmitz, D. (2011). Structural and functional plasticity of the cytoplasmic active zone. Curr. Opin. Neurobiol. 21, 144-150. doi: 10.1016/j. conb.2010.08.012

Siksou, L., Rostaing, P., Lechaire, J. P., Boudier, T., Ohtsuka, T., Fejtová, A., et al. (2007). Three-dimensional architecture of presynaptic terminal cytomatrix. J. Neurosci. 27, 6868-6877. doi: 10.1523/jneurosci.1773-07.2007

Südhof, T. C. (2012). The presynaptic active zone. Neuron 75, 11-25. doi: 10. 1016/j.neuron.2012.06.012

Takao-Rikitsu, E., Mochida, S., Inoue, E., Deguchi-Tawarada, M., Inoue, M., Ohtsuka, T., et al. (2004). Physical and functional interaction of the active zone proteins, CAST, RIM1 and Bassoon, in neurotransmitter release. J. Cell Biol. 164, 301-311. doi: 10.1083/jcb.200307101

Tao-Cheng, J. H. (2007). Ultrastructural localization of active zone and synaptic vesicle proteins in a preassembled multi-vesicle transport aggregate. Neuroscience 150, 575-584. doi: 10.1016/j.neuroscience.2007.09.031

tom Dieck, S., Altrock, W. D., Kessels, M. M., Qualmann, B., Regus, H., Brauner, D., et al. (2005). Molecular dissection of the photoreceptor ribbon synapse: physical interaction of Bassoon and RIBEYE is essential for the assembly of the ribbon complex. J. Cell Biol. 168, 825-836. doi: 10.1083/jcb. 200408157

tom Dieck, S., Sanmarti-Vila, L., Langnaese, K., Richter, K., Kindler, S., Soyke, A., et al. (1998). Bassoon, a novel zinc-finger CAG/glutamine-repeat protein selectively localized at the active zone of presynaptic nerve terminals. J. Cell Biol. 142, 499-509. doi: 10.1083/jcb.142.2.499

Trinidad, J. C., Specht, C. G., Thalhammer, A., Schoepfer, R., and Burlingame, A. L. (2006). Comprehensive identification of phosphorylation sites in postsynaptic density preparations. Mol. Cell. Proteomics 5, 914-922. doi: 10. 1074/mcp.t500041-mcp200

Valente, C., Luini, A., and Corda, D. (2013). Components of the CtBP1/BARSdependent fission machinery. Histochem. Cell Biol. 140, 407-421. doi: 10. 1007/s00418-013-1138-1

Vardinon-Friedman, H., Bresler, T., Garner, C. C., and Ziv, N. E. (2000). Assembly of new individual excitatory synapses: time course and temporal order of synaptic molecule recruitment. Neuron 27, 57-69. doi: 10.1016/S0896-6273 (00)00009-X

Vosseller, K., Trinidad, J. C., Chalkley, R. J., Specht, C. G., Thalhammer, A., Lynn, A. J., et al. (2006). O-linked $\mathrm{N}$-acetylglucosamine proteomics of postsynaptic density preparations using lectin weak affinity chromatography and mass spectrometry. Mol. Cell. Proteomics 5, 923-934. doi: 10.1074/mcp.t500040mcp200
Wagh, D. A., Rasse, T. M., Asan, E., Hofbauer, A., Schwenkert, I., Dürrbeck, H., et al. (2006). Bruchpilot, a protein with homology to ELKS/CAST, is required for structural integrity and function of synaptic active zones in Drosophila. Neuron 49, 833-844. doi: 10.1016/j.neuron.2006. 02.008

Wagh, D., Terry-Lorenzo, R., Waites, C. L., Leal-Ortiz, S. A., Maas, C., Reimer, R. J., et al. (2015). Piccolo directs activity dependent F-actin assembly from presynaptic active Zones via Daam1. PLoS One 10:e120093. doi: 10. 1371/journal.pone.0120093

Waites, C. L., Craig, A. M., and Garner, C. C. (2005). Mechanisms of vertebrate synaptogenesis. Annu. Rev. Neurosci. 28, 251-274. doi: 10.1146/annurev.neuro. 27.070203.144336

Waites, C. L., and Garner, C. C. (2011). Presynaptic function in health and disease. Trends Neurosci. 34, 326-337. doi: 10.1016/j.tins.2011.03.004

Waites, C. L., Leal-Ortiz, S. A., Andlauer, T. F., Sigrist, S. J., and Garner, C. C. (2011). Piccolo regulates the dynamic assembly of presynaptic F-actin. J. Neurosci. 31, 14250-14263. doi: 10.1523/JNEUROSCI.1835-11.2011

Waites, C. L., Leal-Ortiz, S. A., Okerlund, N., Dalke, H., Fejtova, A., Altrock, W. D., et al. (2013). Bassoon and Piccolo maintain synapse integrity by regulating protein ubiquitination and degradation. EMBO J. 32, 954-969. doi: 10.1038/emboj.2013.27

Wang, X., Hu, B., Zieba, A., Neumann, N. G., Kasper-Sonnenberg, M., Honsbein, A., et al. (2009). A protein interaction node at the neurotransmitter release site: domains of Aczonin/Piccolo, Bassoon, CAST and rim converge on the N-terminal domain of Munc13-1. J. Neurosci. 29, 12584-12596. doi: 10. 1523/JNEUROSCI.1255-09.2009

Wang, X., Kibschull, M., Laue, M. M., Lichte, B., Petrasch-Parwez, E., and Kilimann, M. W. (1999). Aczonin, a $550-\mathrm{kD}$ putative scaffolding protein of presynaptic active zones, shares homology regions with Rim and Bassoon and binds profilin. J. Cell Biol. 147, 151-162. doi: 10.1083/jcb.147.1.151

Watanabe, S., Liu, Q., Davis, M. W., Hollopeter, G., Thomas, N., Jorgensen, N. B., et al. (2013a). Ultrafast endocytosis at Caenorhabditis elegans neuromuscular junctions. Elife 2:e00723. doi: 10.7554/eLife.00723

Watanabe, S., Rost, B. R., Camacho-Pérez, M., Davis, M. W., Söhl-Kielczynski, B., Rosenmund, C., et al. (2013b). Ultrafast endocytosis at mouse hippocampal synapses. Nature 504, 242-247. doi: 10.1038/nature12809

Zhai, R. G., Vardinon-Friedman, H., Cases-Langhoff, C., Becker, B., Gundelfinger, E. D., Ziv, N. E., et al. (2001). Assembling the presynaptic active zone: a characterization of an active one precursor vesicle. Neuron 29, 131-143. doi: 10. 1016/S0896-6273(01)00185-4

Zhou, Q., Lai, Y., Bacaj, T., Zhao, M., Lyubimov, A. Y., Uervirojnangkoorn, M., et al. (2015). Architecture of the synaptotagmin-SNARE machinery for neuronal exocytosis. Nature 525, 62-67. doi: 10.1038/nature14975

Ziv, N. E., and Fisher-Lavie, A. (2014). Presynaptic and postsynaptic scaffolds: dynamics fast and slow. Neuroscientist 20, 439-452. doi: 10 . $1177 / 1073858414523321$

Conflict of Interest Statement: The authors declare that the research was conducted in the absence of any commercial or financial relationships that could be construed as a potential conflict of interest.

Copyright (C) 2016 Gundelfinger, Reissner and Garner. This is an open-access article distributed under the terms of the Creative Commons Attribution License (CC BY). The use, distribution and reproduction in other forums is permitted, provided the original author(s) or licensor are credited and that the original publication in this journal is cited, in accordance with accepted academic practice. No use, distribution or reproduction is permitted which does not comply with these terms. 